\title{
Asking structured and focused clinical questions: essential first step of evidence-based practice
}

\begin{abstract}
The aim of evidence-based practice is to help clinicians to base their practice on best current evidence. The essential first step in the process is the identification of uncertainty, or the need for information, and the translation of this uncertainty into answerable clinical questions. Developing the ability to formulate precise, structured, and answerable clinical questions has been identified as one of the key tasks for clinicians using the strategies of evidence-based practice in their clinical work. ${ }^{1}$

The question needs to be:

- Directly relevant to the identified problem

- Constructed in a way that facilitates searching for a precise answer.
\end{abstract}

\section{Example}

A 24 year old man has been admitted to an acute psychiatric ward complaining of hearing voices (3rd person auditory hallucinations) and persecutory ideas. He had a previous admission about six months ago with a similar clinical picture, but he left the hospital before a definitive diagnosis could be made. He also has a past history of substance abuse. He is unwilling to take haloperidol because of an acute dystonic reaction that occurred with this drug during his previous admission. He wants to leave the hospital, but has no accommodation and the clinical team have concerns about the content of his hallucinations.

Most clinicians generate several clinical questions when they are presented with this example. Some of these questions can only be answered by obtaining more information from the patient, for example does the patient have any depressive symptoms? Has the patient been taking psychoactive drugs recently? This sort of question is obviously important to identify the patient's problems, to understand them, and to help to put them into context.

However, many questions can only be answered by using research that has been done with similar groups of patients with similar problems. Examples of this kind of question include:

- What is the likely diagnosis on the basis of the presenting symptoms?

- What are the implications of the substance abuse for diagnosis, treatment, and prognosis?

- Is there a treatment which would be less likely to cause extrapyramidal side effects than haloperidol?

- Is there any way that the patient's concordance with treatment can be improved?

- What is likely to happen if the patient leaves hospital?

Here, we will focus mainly on this second category of question.

As in the example, most patients generate at least some clinical uncertainty-perhaps several questions. It seems that clinicians both underestimate their information needs and have difficulty in getting satisfactory answers. ${ }^{2}$ Clinicians may find it difficult to acknowledge uncertainty, and developing the requisite skills is likely to take practice and some coaching. ${ }^{3}$ In practice, once we begin to recognise uncertainties and knowledge gaps, the number of questions seems to grow exponentially! When many questions arise, clinicians therefore need to prioritise their information needs. Choosing which question to answer first will depend on which question:

- Is most important for the patient's wellbeing

- Is likely to be feasible to answer within the time available

- Is the most interesting

- Is likely to arise frequently in practice. ${ }^{4}$

\section{Structure and classification of clinical questions}

Before looking for the answer, the question needs to be formulated into a precise, structured question. This involves breaking the question down into 3 (or 4 in the case of treatment questions) components:

(1) The patient's problem: this will often be a diagnosis, but may be a non-diagnostic problem such as a lack of housing

(2) The intervention of interest: in treatment questions this will be an intervention, in diagnostic questions it may be any aspect of the history or examination

(3) The comparison intervention: in treatment questions

(4) The outcomes of interest.

In the example, the first question is to do with diagnosis and would become:

If a patient with psychotic symptoms (and therefore a high pre-test probability of schizophrenia) (problem) clearly describes a hallucinatory voice talking in the third person (intervention), how likely is it that the illness will meet reliable criteria for schizophrenia when the assessment is complete (outcome)?

The third question is one of treatment and would become: In a patient with a working diagnosis of schizophrenia (problem) how well does an atypical antipsychotic such as olanzapine or risperidone (intervention), compared with haloperidol (comparison intervention), reduce psychotic symptoms without causing unacceptable extrapyramidal side effects (outcome)?

Most commonly occurring clinical questions are those of treatment (which treatment is most likely to increase the probability of a desired outcome?), diagnosis (what is the most helpful way of classifying a patient's problem?), and prognosis (how likely is it that specific outcomes will occur?). Table 1 shows the general forms of these questions.

\section{Architecture of research}

Once the question has been structured and classified, this indicates the research design that is most likely to produce reliable answers (table 1). Furthermore, a hierarchy of 


\begin{tabular}{|c|c|c|}
\hline $\begin{array}{l}\text { Type of } \\
\text { question }\end{array}$ & Form of the question & Most reliable study architecture \\
\hline Diagnosis & $\begin{array}{l}\text { How likely is a patient who has a particular symptom, sign } \\
\text { or diagnostic test result to have a specific disorder? }\end{array}$ & $\begin{array}{l}\text { A cross sectional study of patients suspected of having the disorder comparing the } \\
\text { proportion of the patients who really have the disorder who have a positive test with the } \\
\text { proportion of patients who do not have the disorder who have a positive test result. }\end{array}$ \\
\hline Treatment & $\begin{array}{l}\text { Is the treatment of interest more effective in producing a } \\
\text { desired outcome than an alternative treatment } \\
\text { (including no treatment)? }\end{array}$ & $\begin{array}{l}\text { Randomised evidence in which the patients are randomly allocated to receive either } \\
\text { the treatment of interest of the alternative (table } 2 \text { ) }\end{array}$ \\
\hline Prognosis & $\begin{array}{l}\text { What is the probability of a specific outcome in this } \\
\text { patient? }\end{array}$ & $\begin{array}{l}\text { A study in which an inception cohort (patients at a common stage in the development } \\
\text { of the illness-especially first onset) are followed up for an adequate length of time }\end{array}$ \\
\hline Aetiology & $\begin{array}{l}\text { What has caused the disorder? (or, how likely is a } \\
\text { particular intervention to cause a specific adverse } \\
\text { effect?) }\end{array}$ & $\begin{array}{l}\text { A study comparing the frequency of an exposure in a group of people with the } \\
\text { disease (cases) of interest with a group of people without the disease (controls)--this } \\
\text { may be a randomised controlled trial, a case control study, or a cohort study. }\end{array}$ \\
\hline
\end{tabular}

\section{Table 2 Hierarchy of research for treatment studies}

\begin{tabular}{ll} 
Ia: & Evidence from a systematic review of randomised controlled trials \\
Ib: & Evidence from at least one randomised controlled trial \\
IIa: & Evidence from at least one controlled study without randomisation \\
IIb: & Evidence from at least one other type of quasi-experimental study \\
III: & $\begin{array}{l}\text { Evidence from non-experimental descriptive studies, such as } \\
\text { comparative studies, correlation studies, and case control studies }\end{array}$ \\
IV: & $\begin{array}{l}\text { Evidence from expert committee reports or opinions and/or } \\
\text { clinical experience of respected authorities }\end{array}$ \\
\hline
\end{tabular}

research design can be constructed for each kind of clinical question. Such a hierarchy is best established for treatment questions (table 2), but the general principle is that a systematic review of all available high quality studies is likely to be the most reliable evidence for any kind of question. So for a treatment question, a valid systematic review of randomised controlled trials would come at the top of the hierarchy, and for a prognosis question it would be a systematic review of inception cohort studies.

Identifying the most reliable research design will also help efficient searching-a subject we will cover in a future EBMH note.

The structured clinical question is therefore a useful way of linking clinical uncertainty to research evidence. To facilitate this process in the evidence-based journals, we have replaced the objective section of the abstracts with the structured clinical question that the research was primarily designed to answer." As well as helping individual clinicians to find rapidly the best available evidence, an active attempt to identify areas of clinical uncertainty is likely to bring another benefit. When it is clear that a substantial number of clinicians have clinical uncertainty about a clinical question, even when the best available evidence has been identified, this question becomes a priority for further research. These research priorities can then be fed into the systems of health technology assessment described by Ken Stein and Ruiaridh Milne in this issue.

JOHN GEDDES, MD Editor, Evidence-Based Mental Health

\footnotetext{
1 Richardson S. The well-built clinical question: a key to evidence-based decisions [editorial]. ACP J Club 1995 Nov-Dec;1 123:A12-3.

2 Smith R. What clinical information do doctors need? $B M J 1996 ; 313$ : 1062-8.

3 Richardson WS. Ask, and ye shall retrieve [EBM note]. Evidence-Based Medicine 1998 Jul-Aug;3:100-1.

4 Sackett DL, Richardson WS, Rosenberg W, et al. Evidence-based medicine: how to practise and teach EBM. London: Churchill-Livingstone, 1997.
}

\section{EBMH feedback on the web}

We welcome letters from our readers about Evidence-Based Mental Health. Your feedback is most important in assisting us to produce a high quality journal which is useful to the practising mental health clinician. All letters will be put up on the web site; for the latest feedback please go to http://www.psychiatry.ox.ac.uk/cebmh/journal/letters.html

All letters should be typewritten, double spaced, and mailed or faxed to Nancy Wilczynski in the Canadian editorial office (Health Information Research Unit, Faculty of Health Sciences, McMaster University, HSC 3H7, Hamilton, Ontario L8N 3Z5, Canada. Fax + 1905546 0401). 